University of Nebraska - Lincoln

DigitalCommons@University of Nebraska - Lincoln

2006

The pea aphid, Acyrthosiphon pisum: An emerging genomic model system for ecological, developmental, and evolutionary studies

\author{
Jennifer A. Brisson \\ University of Nebraska-Lincoln, jennifer.brisson@rochester.edu \\ David L. Stern \\ Princeton University
}

Follow this and additional works at: https://digitalcommons.unl.edu/bioscifacpub

Part of the Life Sciences Commons

Brisson, Jennifer A. and Stern, David L., "The pea aphid, Acyrthosiphon pisum: An emerging genomic model system for ecological, developmental, and evolutionary studies" (2006). Faculty Publications in the Biological Sciences. 70.

https://digitalcommons.unl.edu/bioscifacpub/70

This Article is brought to you for free and open access by the Papers in the Biological Sciences at DigitalCommons@University of Nebraska - Lincoln. It has been accepted for inclusion in Faculty Publications in the Biological Sciences by an authorized administrator of DigitalCommons@University of Nebraska - Lincoln. 


\title{
The pea aphid, Acyrthosiphon pisum: An emerging genomic model system for ecological, developmental, and evolutionary studies
}

\author{
Jennifer A. Brisson and David L. Stern \\ Department of Ecology and Evolutionary Biology, Princeton University, Princeton, NJ 08540, USA \\ Corresponding author — Jennifer A. Brisson
}

\begin{abstract}
Aphids display an abundance of adaptations that are not easily studied in existing model systems. Here we review the biology of a new genomic model system, the pea aphid, Acyrthosiphon pisum. We then discuss several phenomena that are particularly accessible to study in the pea aphid: the developmental genetic basis of polyphenisms, aphid-bacterial symbioses, the genetics of adaptation and mechanisms of virus transmission. The pea aphid can be maintained in the laboratory and natural populations can be studied in the field. These properties allow controlled experiments to be performed on problems of direct relevance to natural aphid populations. Combined with new genomic approaches, the pea aphid is poised to become an important model system for understanding the molecular and developmental basis of many ecologically and evolutionarily relevant problems.
\end{abstract}

\section{Introduction}

Aphids are small insects $(1-10 \mathrm{~mm})$ with soft bodies characterized by a pair of long antennae, a piercing-sucking proboscis and a pair of upward-pointing tubes on the dorsal fifth abdominal segment called siphunculi, which excrete alarm pheromones. Aphids are members of the order Hemiptera, along with true bugs, cicadas and leafhoppers. Although aphids evolved at least 280 million years ago, the majority of extant species arose from a radiation that began approximately 140 million years ago, concurrent with the diversification of the angiosperms. ${ }^{(1-}$ 3) Approximately 4,400 species of aphids are currently known and most live in northern temperate regions. ${ }^{(4)}$ They are one of the few groups of insects that are more abundant in temperate regions than in the tropics. Nearly 250 species feed on agricultural crops and cause an estimated hundreds of millions of dollars in lost production each year. ${ }^{(5)}$ Among these, gardeners frequently en- counter the greenfly (Macrosiphum rosae) on rosebushes or the black bean aphid (Aphis fabae) on other garden plants.

Aphids have been popular with both field and laboratory biologists in the last century in part because they display multiple intraspecific phenotypic morphs, they have complex life cycles that alternate between sexual and asexual reproduction, and they rapidly evolve hostplant associations. With the recent development of genomic resources, aphids are becoming a model system for using molecular approaches to study these diverse, ecologically relevant phenomena. Here we focus on our favorite species of aphid, the pea aphid Acyrthosiphon pisum. We begin by describing the pea aphid's complex life cycle and its suitability for laboratory life. We then discuss two of the main pea aphid research pursuits in our laboratory: the molecular genetic basis of extreme developmental plasticity and insect-bacterial symbiosis. We conclude by presenting two additional research subjects for which pea aphids are suited: the genetics of adaptation and plant-virus transmission. This is, by no means, a complete survey of research on aphids and readers can find more information in a number of resources. $(4,6-10)$

\section{Our favorite species: the pea aphid}

Pea aphids belong to the family Aphididae, subfamily Aphidinae. The species was originally palearctic in distribution, but they have been introduced, probably many times, to the New World within the last two hundred years. (11) Although most pea aphids feed on a range of host plants in the pea family (Leguminosae), a number of different host races exhibit a clear preference for, and display increased fitness on, specific plants such as alfalfa or clover. ${ }^{(4,12)}$ 


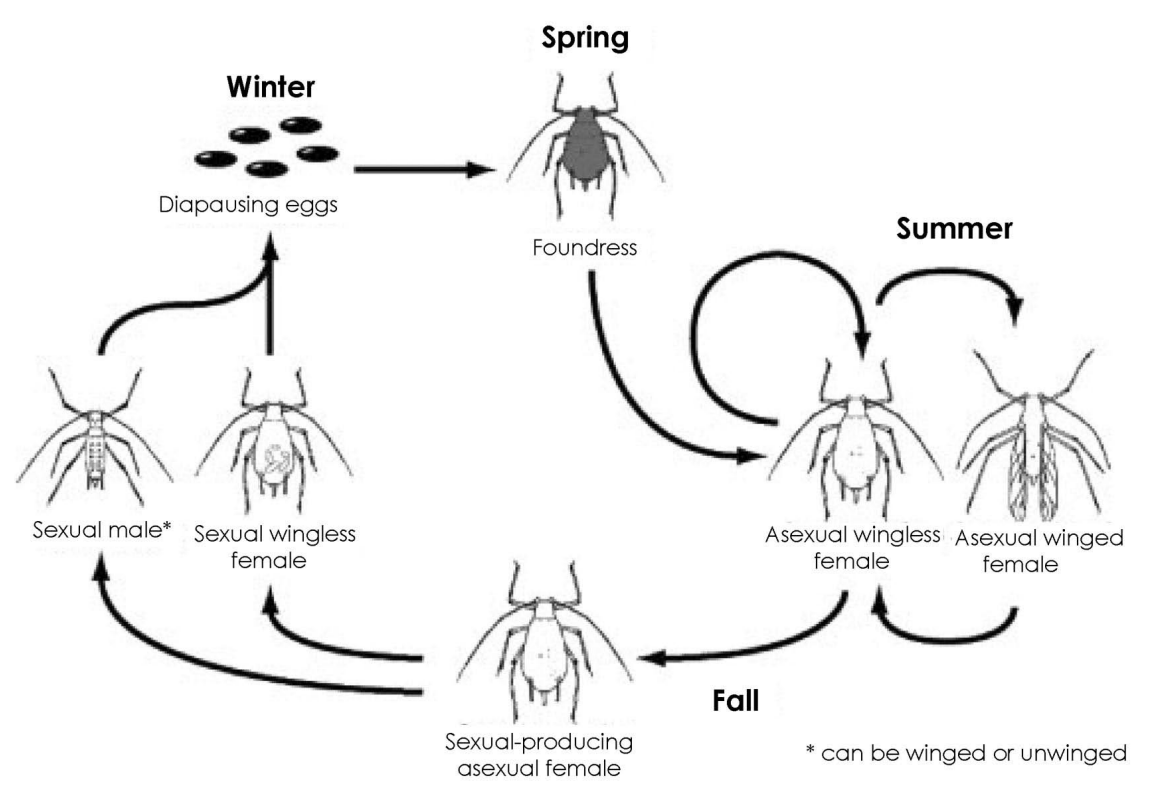

Figure 1. The life cycle of the pea aphid. In the summer, asexual females can be winged or unwinged. In the fall, asexual females give rise to sexual males that can be winged or unwinged, and sexual wingless females. Mating results in an overwintering egg that in the spring produces an asexual foundress female. (C) 2003 Alexander Shingleton et al. http://www.biomedcentral.com/1471-213X/3/7

As hemimetabolous insects, pea aphids undergo incomplete metamorphosis. Like many aphid species, they have a complex life cycle that alternates between asexual and sexual reproduction (Figure 1). During the summer months, pea aphids reproduce via parthenogenesis with no recombination. They produce genetically identical daughters that develop through four nymphal instars before molting into an adult. (13) Colonies of aphids descended from a single mother are therefore often, and appropriately, called a clone. The clonal nature of aphid colonies provides important advantages for studying traits such as host plant preference and fitness, since experiments can be replicated with genetically identical individuals.
Embryos complete development within the mother, who gives live birth to first instar nymphs (viviparous parthenogenesis). Multiple embryos develop sequentially within each ovariole (Figure 2). In addition, late-stage embryos have embryos developing already within them, a condition referred to as telescoping of generations. Females begin producing offspring 7-15 days following birth. This short generation time, combined with the telescoping of generations, results in rapid growth of colonies that can quickly exploit a host plant

In the fall, shorter days and colder temperatures cue the development of two additional morphs: sexual females and males. Males are formed by a modified meiosis in which one of the $X$ chromosomes is lost during

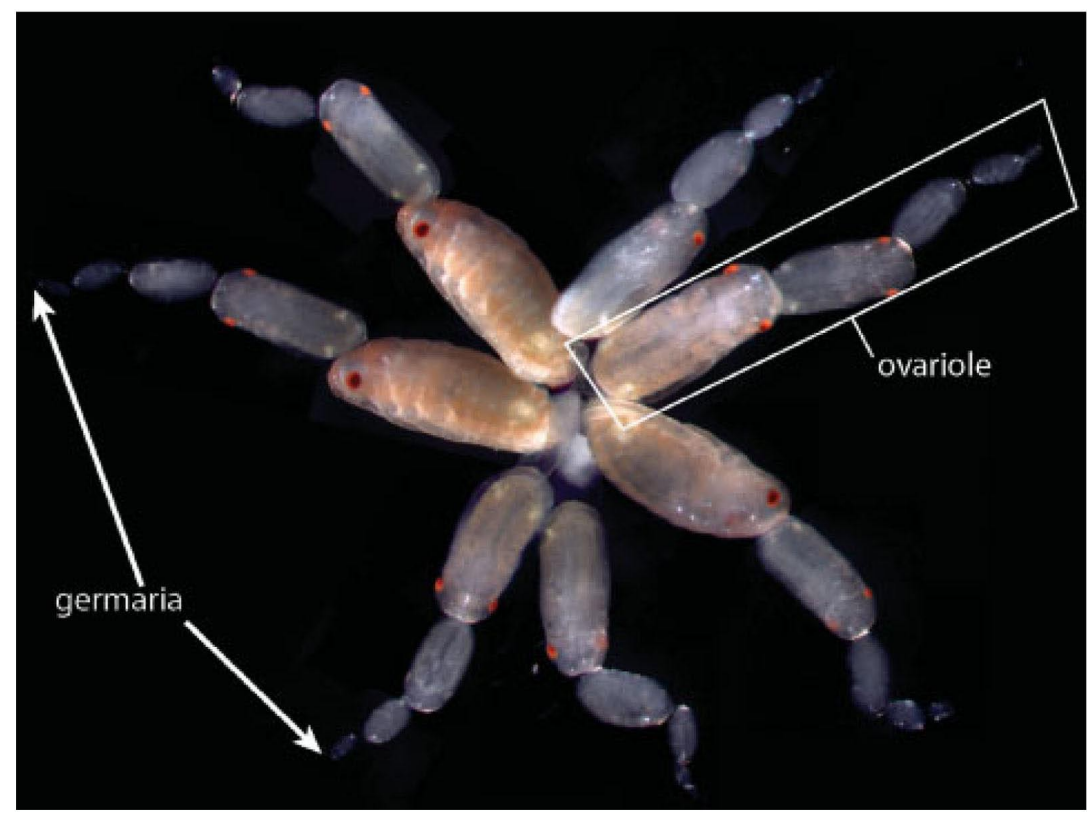

Figure 2. Dissected ovary of the pea aphid. The germaria are located at the tips of the ovarioles, as indicated. Aphids develop serially within individual ovarioles, and the developmental stage of embryos is staggered between ovarioles such that a range of developmental stages can be observed in a single ovary. Photo by Jim Truman. Reproduced from Miura T, Braendle C, Shingleton A, Sisk G, Kambhampati S et al. 2003 J Exp Zool B Mol Dev Evol 295B:59-81. (C) John Wiley \& Sons. 
oogenesis. ${ }^{13,14)}$ Loss of one or the other $X$ chromosome is equally probable in pea aphids. ${ }^{(15,16)}$ Hence, the sole genetic difference between male offspring and their mother is that they carry only one of her $\mathrm{X}$ chromosomes.

All fertilized eggs produce female (XX) offspring, presumably because sperm produced by males survive only if they carry an X chromosome. The egg is laid before or soon after embryogenesis has begun, in contrast to the parthenogenetic forms in which embryogenesis is completed before birth. After 14 days, the egg enters a diapause period in which the embryo's development slows considerably. Although the diapause is presumably an adaptation to cold winters and eggs require this cold period to develop normally, the slow development of the embryo is temperature independent and proceeds at a slow rate even at higher temperatures.(17) In the spring, asexual females hatch approximately 100 days after the eggs were laid.

\section{Pea aphids in the laboratory}

Pea aphids have been used in the laboratory setting for a range of genetic and physiological studies. ${ }^{(18-20)}$ Parthenogenetic lineages can be maintained perpetually in incubators that replicate summer-like conditions. Experimental manipulations can therefore be performed on clonal sibling replicates. Further, recent innovations in aphid-rearing techniques have simplified stock maintenance: pea aphids can be fed on leaves of Medicago arborea, a perennial and hardy alfalfa, that have been inserted into agar containing Miracle-Gro in small plastic plates. Pea aphids are particularly suited to this culture system because they utilize only a single host plant during their life cycle (in contrast to many aphids that require two species of host plants, reviewed by Moran(9)). Sexuals can be induced by transferring aphids to an incubator with short days and colder temperatures, allowing genetic crosses. ${ }^{(20-22)}$

\section{Polyphenisms in the aphid}

Polyphenisms are defined as discrete alternative morphologies produced from the same genotype. Well-studied insect polyphenisms include social insect castes, (23) seasonal wing patterns in butterflies(24) and horn size in beetles. ${ }^{(25)}$ Polyphenic forms in different aphid species include alternative morphs on different host plants, winged versus unwinged morphs, parthenogenetic versus sexval reproductive morphs, specialized altruistic soldier nymphs ${ }^{(26)}$ and aestivating forms. (27) Parthenogenetic morphs found on the alternative host plants of host-alternating species can vary so dramatically that the different morphs were sometimes originally classified as separate genera. This environmentally induced intraspecific diversity is a unique feature of aphids relative to many other laboratory species. Aphids are therefore an emerging model system to examine how developmental pathways encoded by a single genome can evolve to pro- duce adaptive alternative morphologies. The pea aphid exhibits two polyphenisms, which have been the focus of our research: the wing polyphenism and the asexual versus sexual polyphenism.

\section{The wing polyphenism in the pea aphid}

Many aphid species display a wing dimorphism, with the unwinged versus winged morphs exhibiting a trade-off between reproduction and flight. ${ }^{(28)}$ The characterization of this polyphenism as a wing dimorphism is simplistic, however, and is perhaps better considered a more general morphological dimorphism related to dispersal because in fact many aspects of the phenotype are dimorphic. ${ }^{(29)}$ For example, winged morphs have ocelli on the vertex of their head and greatly expanded thoraces with flight musculature, whereas unwinged morphs do not. Also, the cuticle of the winged morph is more heavily sclerotized than that of the unwinged morph and the dimensions of the legs and siphunculi differ. Moreover, the two morphs exhibit different behavior: winged individuals are active in colonizing new host plants, while unwinged morphs are mostly sedentary. The wingless morph has a shorter generation time and higher fecundity than the winged morph (reviewed in Muller et al(30)).

Parthenogens typically develop without wings. A number of different stimuli can cause these females to produce winged daughters. First, winged forms can be induced under food-stressed conditions, such as when host-plant quality declines or a plant becomes overcrowded. ${ }^{(18)}$ These winged offspring can then fly to new plants. Second, winged offspring can be induced as a defense mechanism: aphid colonies that have been exposed to parasitoids produce more winged offspring, (31) as do colonies that have encountered common predators such as ladybirds or the larvae of lacewings and hoverflies(b) or that have been exposed to the pea aphid alarm pheromone (E)- $\beta$-farnesene. ${ }^{(32)}$ These two types of induction may have the same physical basis(33) as the environmental cue seems to be transduced primarily by physical contact, probably through the adult antennae:(18) in both cases, aphids display more active behavior (either to find food, or to avoid parasitization/predation) which leads to more touching of antennae.

All embryos initiate the development of wing buds, but these wing buds degenerate after the second nymphal instar in individuals destined to become unwinged. ${ }^{(34)} \mathrm{De}-$ spite this developmental evidence that the winged form is the default state, aphids produce winged forms only in response to the environmental cues previously mentioned. In the pea aphid, these cues are perceived by the mother who then transmits a permissive signal to her embryos to develop with wings. (18) Only embryos that are approximately 24 to 48 hours from birth can respond to this signal; nymphs cannot be induced to produce wings in the pea aphid although, in other species, wings can be induced up to the third nymphal instar. $(30,35,36)$ 
Male pea aphids, and males of several other aphid species, also show a wing dimorphism. But, in contrast to the environmentally cued wing polyphenism in parthenogenetic females, an X-linked genetic polymorphism at the aphicarus (api) locus determines wing morphs in pea aphid males. ${ }^{(16,20)}$ Despite this essential difference in the cause of alternative morphs in females and males, the phenotypes of the winged and unwinged individuals are superficially similar, including similarities in the wing musculature, cuticular sclerotization and behavior (Figure 3). There remain some differences, however, between the female and male dimorphisms. For example, in males, both the winged and unwinged forms have ocelli while, in females, only the winged morphs have ocelli, and the antennae of both male forms are similar to the winged female antennae. (29)

Curiously, naturally segregating variation for the female polyphenism is genetically linked to the male polymorphism; crowded parthenogenetic females with at least one copy of the api unwinged allele produce more winged daughters than females homozygous for the api winged allele. (37) Therefore, at least one gene that has a major effect on the environmentally cued polyphenism is genetically linked to api.

We currently have essentially no understanding of the molecular mechanisms regulating the wing dimorphism in either males or females. Previous studies of the potential roles of insect hormones such as ecdysone and juve- nile hormone have provided equivocal results (reviewed in C. Braendle et al., unpublished data). Genes that regulate wing development, such as those studied in relation to the winged or unwinged state of ant castes, (38) are of interest but unlikely to control the systemic phenotypic differences associated with the two morphologies. This problem is, therefore, wide open to study with genomic and genetic approaches.

The polyphenism of asexual versus sexual development in the pea aphid

In autumn, decreasing photoperiods and cooler temperatures induce the production of yet another specific morph, the sexual-producing asexual female. This asexual female then produces sexual males and females. Sexual and asexual females differ in a number of ways, such as the lack of accessory glands and spermathecae in asexvals. The principal difference between the two, however, is the presence of haploid oocytes in sexual females and developing embryos within the ovarioles of parthenogenetic females. Again, there is little understanding of the molecular mechanisms regulating this polyphenism, although there is good evidence from studies of a related species that juvenile hormone is involved. (39)

Embryonic development has been described for several aphid species, ${ }^{(13,40)}$ and the details of sexual, oviparous versus parthenogenetic, viviparous development in the pea aphid can be found in Miura et al (References

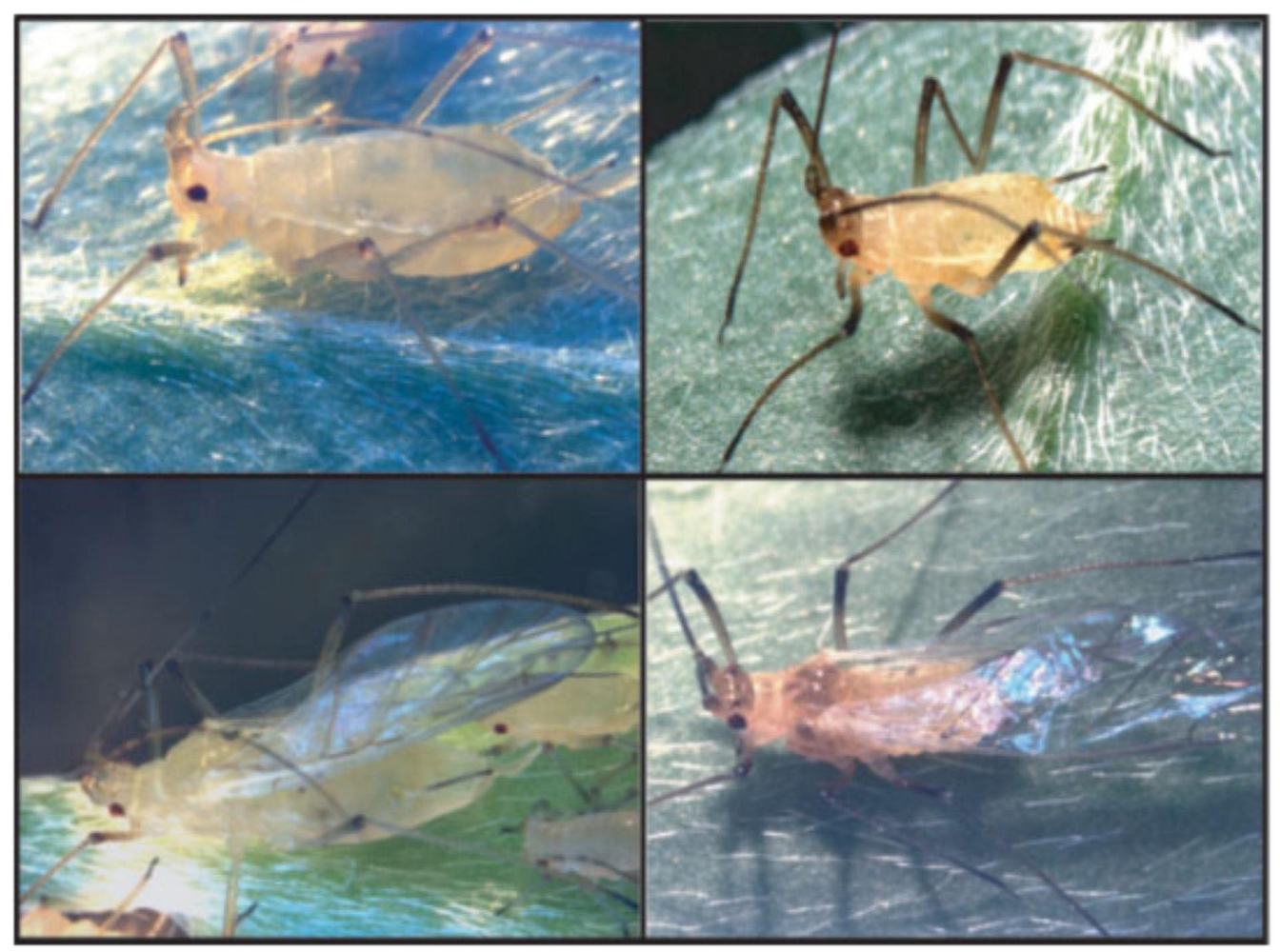

Figure 3. The female polyphenism (left) and male genetic polymorphism (right). In both cases, discrete alternative unwinged (top) or winged (bottom) morphs are produced. 
17 and 41 and references therein). These divergent modes of reproduction involve several obvious differences. At early stages of embryonic development, the parthenogenetic embryo is approximately $60 \mu \mathrm{m}$ long, whereas the embryo in a sexually produced egg resides in an egg approximately $1 \mathrm{~mm}$ long, a difference in volume of over two orders of magnitude. Asexual development proceeds within a yolk-free environment due to direct nutrient input by the mother, whereas the embryo in a sexually produced egg derives all of its nutrition from yolk. Finally, the rate of development differs dramatically, with embryos in sexually produced eggs developing for 80 to 140 days while the parthenogenetic embryos develop for only 10 to 15 days. Despite differences in size, maturation time and location, the two modes of development produce virtually identical first instar nymphs. Determining which developmental processes are conserved and which have diverged to accommodate these differences is a promising area of ongoing research.

The parthenogenetic mode of reproduction in aphids evolved from exclusively sexually reproducing forms more than 200 MYA..$^{(9,42)}$ In parthenogens, the oocyte undergoes a single meiotic division, producing a single polar body, rather than two divisions to produce a haploid egg as in the sexual female. With no evidence for recombination, (43) and no loss of heterozygosity, (44) this division resembles meiosis II, rather than meiosis I. Parthenogenesis thus appears to have evolved via a modified meiosis. Although the pea aphid alternates facultatively between the two modes of reproduction, a large number of aphid species have lost the sexual phase of their life cycle $e^{(9,45,46)}$ and many species that alternate reproductive forms do so only in the northern parts of their range. Obligately parthenogenetic aphids avoid the evolutionary cost of making males but do not benefit from recombination, $(47,48)$ and may incur high rates of mortality over the winter due to the absence of cold-tolerant eggs. Thus, aphids provide a unique opportunity to examine the role of sex and recombination over long-term evolution.

\section{The aphid-Buchnera symbiosis}

Pea aphids require the intracellular bacteria Buchnera aphidicola for their survival and reproduction. Such endosymbioses are common in insects, with more than $10 \%$ of insect species relying upon intracellular bacteria for some aspect of their livelihood.(49) There are several excellent reviews of the biology and genomics of $B$. aphidicola. ${ }^{(49-52)}$ Here we outline basic features of the aphidBuchnera association and focus on the developmental process by which bacteria are passed from mother to offspring.

The aphid-Buchnera symbiosis represents a particularly intimate form of symbiosis in which B. aphidicola lives permanently within host cells. This advanced stage of symbiosis is similar to the presumptive early stages of plastid evolution. Similar to plastids, the genome of B. aphidicola has undergone extensive gene loss since the symbiont's ancestor invaded aphids. (53-55) The bacterial genome has lost many genes required for autonomous survival and now appears to be focused on recycling nitrogen and providing essential amino acids for aphids.

B. aphidicola are evolutionarily derived from free-living bacteria(49) and both the aphid and the symbiont must have evolved mechanisms for integrating the bacteria into the workings of the cell. B. aphidicola live within large polyploid cells, called bacteriocytes, which are grouped into an organ-like structures called the bacteriome located adjacent to the ovarioles. During parthenogenetic development, maternal bacteria are deposited within a syncytium in the center of the blastoderm embryo through an opening in the posterior of the follicular epithelium (Figure 4). ${ }^{(41,56)}$ The nuclei within this syncytium (the presumptive bacteriocyte nuclei) express an unusual combination of transcription factors, such as Distalless and engrailed, although it is not yet known if expression of these transcription factors is required to determine the bacteriocyte fate.(57) Nonetheless, the unique transcriptional state of these cells suggests that this novel cell type has evolved by co-opting expression of transcription factors normally expressed at other times and places in development.

This syncytium then develops into cellularized bacteriocytes, each containing a single nucleus and many bacterial cells. The bacteriocyte nuclei subsequently undergo endoreduplication and become polyploid. Later in development, a separate population of nuclei in the dorsal posterior region of the embryo begins to express at least some of the same transcription factors that characterize the early syncytial nuclei. These nuclei, which may have already cellularized, then migrate across the germ band until they make contact with the original bacteriocytes. These new bacteriocyte cells then somehow take up bacterial cells from the original bacteriocytes and become polyploid. This bizarre two-stage development of bacteriocytes is not unique to pea aphids, but is also found in some of the most distantly related aphids, suggesting that this developmental process was present in the common ancestor of aphids.

Bacteriocyte development is at least superficially different in the eggs produced by the sexual females. In the sexual stage, the bacteria are deposited in the posterior pole of the developing oocyte prior to fertilization. This package of bacteria is maintained at the posterior pole through unknown mechanisms until the embryo begins development. We currently have little insight into how the bacteria are packaged into bacteriocytes within the sexual egg, and we do not yet know whether this process involves a two-step recruitment of bacteriocyte cells, as during parthenogenetic development.

In addition to the obligate symbiont Buchnera, at least five facultative bacterial symbionts have also been found in different strains of the pea aphid. These sym- 


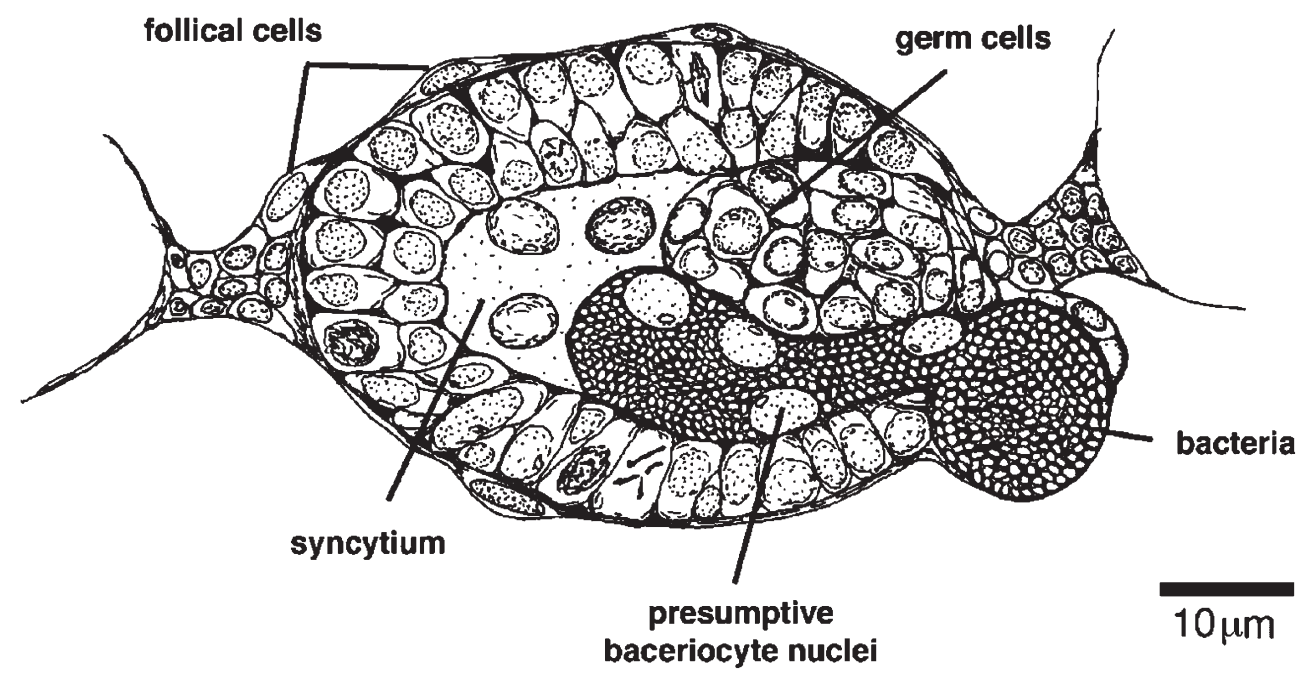

Figure 4. Maternal endosymbotic bacteria transfer during parthenogenetic development. Bacteria are deposited into the blastoderm syncytium via an opening in the posterior of the follicular epithelium. Reproduced from Miura T, Braendle C, Shingleton A, Sisk G, Kambhampati S et al. 2003 J Exp Zool B Mol Dev Evol 295B:59-81. (c) John Wiley \& Sons.

bionts have strong effects on aphid fitness that is mediated through a variety of surprising mechanisms such as resistance to elevated temperature, ${ }^{(58)}$ parasitoid resistance, ${ }^{(59,60)}$ host plant specialization ${ }^{(61)}$ and induction of winged forms. ${ }^{(62)}$ While these effects of the facultative symbionts are clearly of ecological and evolutionary significance, there is, as yet, little molecular understanding of how the bacteria provide these advantages.

\section{The pea aphid as a model for studying the molecular genetics of adaptation}

Pea aphids present at least two excellent opportunities for studying the molecular genetic basis of contemporary adaptation. First, like many pest insects, more than twenty aphid species have adapted to the treatment of crops with pesticides by evolving insecticide resistance. In most cases, insecticide resistance has arisen either by an increase in detoxification enzymes (hydrolases especially esterases, glutathione S-transferases or cytochrome P450-dependant monooxygenases) or by mutation of the genes encoding the target-site proteins [acetylcholinesterase (AChE) sodium channels and the GABA receptor] (for reviews see References 63-66). The best-studied example is in Myzus persicae, where amplification of esterase genes, (67) altered AChE and insensitive sodium channels confer resistance, with the three mechanisms often occurring together. ${ }^{(68)}$ In the case of altered AChE, the situation has been complicated by the fact that some aphids, unlike Drosophila and the housefly, have at least two loci encoding AchE. (69)

Many of the mutations conferring resistance of the target proteins are shared between species. ${ }^{(70-72)}$ Thus, insights into the molecular nature of insecticide resistance in the pea aphid are likely to be transferable to closely related major agricultural pest species, such as the peach- potato aphid (Myzus persicae) and the Russian wheat aphid (Diuraphis noxia).

A second opportunity for studying the genetics of adaptation in pea aphids is related to their specificity to particular host plants. Although pea aphids feed on many host plants, some colonies represent host races specialized to feed on either alfalfa or clover. Populations feeding on the two host species can show extensive genetic divergence, even in adjacent fields. ${ }^{(73)}$ In addition, populations specialized on clover show significantly decreased fitness on alfalfa and vice versa. ${ }^{(74)}$ Because mating takes place on the host plant, aphid host plant usage causes assortative mating, which could result in speciation. ${ }^{21,22,75)}$ The detection of host plants by aphids has been studied extensively using electrophysiological techniques, and many of the host cues are known. (76) However, very little is known about the biochemical or molecular basis of olfaction in aphids. In Drosophila melanogaster and Anopheles gambiae, olfaction involves both odorant-binding proteins (OBPs), which bind the odors in the antennal lymph, ${ }^{(77,78)}$ and odorant-receptors (ORs) on the antennal neurons. ${ }^{(79,80)}$ For aphids, there has been one report of chemosensory proteins, ${ }^{(81)}$ but to date no OBPs have been found.

\section{Plant virus transmission}

Aphids cause most agricultural damage not directly by feeding, but rather because they vector plant viruses. Because winged morphs can traverse large areas via active flight or passive migration in upper air currents (as far as $1000 \mathrm{~km}$ in a single flight(82) , they are efficient vectors. Aphids transmit hundreds of plant viruses, and the pea aphid itself transmits more than 30 viruses..$^{(4)}$ Aphids thus provide a model for the study of the mechanisms and dynamics of infectious disease. 
Virus transmission is directly related to aphid feeding and categorized into two primary forms. Most viruses are transmitted in the non-circulative, or stylet-borne manner, in which the aphid probes the epidermis of an infected plant with its piercing-sucking mouthparts and the viral capsules attach to the anterior part of the alimentary tract of the aphid. ${ }^{(83)}$ In this type of transmission, the aphid is immediately but transiently infected, and can subsequently release the virus on uninfected plants by further probing. This type of transmission requires association between viral capsid protein domains and structures of the aphid mouthparts, $(84,85)$

Alternatively, an aphid becomes infected with a circulative virus when it actually feeds from (not just probes) an infected plant and viral particles cross aphid cell membranes through a receptor-assisted endocytosis-exocytosis mechanism. ${ }^{(86,87)}$ The virus, which may or may not replicate within the aphid, then enters the salivary glands and can be injected into additional plants upon subsequent feeding. Aphid proteins that are linked to transmission efficiency have been found and, in a curious twist, one of these is a protein produced by the primary symbiont, Buchnera aphidicola, and apparently excreted from bacteriocytes. ${ }^{(88,89)}$ Some of these proteins are able to specifically bind transmissible virus particles and may therefore represent putative virus receptors. ${ }^{(90)}$ Furthermore, genetic crosses have demonstrated that different aphid genotypes have different propensities to transmit viruses. ${ }^{(91)}$

\section{Conclusion}

We have reviewed the utility of the pea aphid as a model species for studying a range of biological phenomena including polyphenisms, insect-bacterial symbioses and bacteriocyte development, the genetics of adaptation and plant virus transmission. We have discussed only a few of the many features that make pea aphids an exciting model system. Future and ongoing work on these topics will be facilitated by a number of genomic resources, including a large number of expressed sequence tags (available at dbEST: http://www.ncbi.nlm.nih.gov/dbEST/) and the imminent sequencing of the pea aphid genome (http://www.genome.gov/13014443). For example, we are currently utilizing pea aphid cDNA microarrays developed from the EST database to assay how asexually reproducing aphids respond to wing-inducing cues at the transcriptional level. We are also examining the transcriptional profiles of the resulting winged and unwinged offspring at different stages of development.

To keep up to date with ongoing developments in pea aphid genomics, interested individuals can learn more about the International Aphid Genome Consortium < http://www.princeton.edu/ dstern/IAGC > and can join the aphid genomics listserver < http://www.eco.princeton.edu/mailman/listinfo/aphidgenomics $>$.

\section{Acknowledgments}

This work was supported by a grant from the $\mathrm{NIH}$, funds from Princeton University and a David \& Lucile Packard Foundation Fellowship to DLS. We thank Linda Field for generously contributing much of the section on the molecular genetics of adaptations. We also thank R. Bickel, G. Davis, T. Leonardo, and A. Shingleton for comments on the manuscript.

\section{References}

1. Heie OE. 1987. Paleontology and phylogeny. In: Minks AK, Harrewijn P, editors. Aphids: Their Biology, Natural Enemies, and Control. Amsterdam: Elsevier.

2. Heie OE. 1996. The evolutionary history of aphids and a hypothesis on the coevolution of aphids and plants. Bollettino Di Zoologia Agraria E Di Bachicoltura 28:149-155.

3. Von Dohlen CD, Moran NA. 2000. Molecular data support a rapid radiation of aphids in the Cretaceous and multiple origins of host alternation. Biol J Linn Soc 4:689-717.

4. Blackman RL, Eastop VF. 2000. Aphids on the world's crops: an identification and information guide. Chichester: John Wiley \& Sons Ltd.

5. Oerke EC. 1994. Estimated losses in major food and cash crops. In: Oerke EC, Dehne HW, Schonbeck F, Weber A, editors. Crop production and crop protection. Amsterdam: Elsevier.

6. Dixon AFG. 1998. Aphid Ecology. London, UK: Chapman \& Hall.

7. Minks AK, Harrewijn P. 1980. Aphids, their biology, natural enemies, and control. Amsterdam: Elsevier.

8. Heie OE. 1980. The Aphidoidea (Hemiptera) of Fennoscandia and Denmark. 1. General Part. The families Mindaridae, Hormaphididae, Thelaxidae, Anoeciidae, and Pemphigidae. Fauna Ent. Scandinavica 9:

9. Moran NA. 1992. The evolution of aphid life cycles. Ann Rev Ent 37:321-348.

10. Blackman RL, Eastop VF. 1994. Aphids on the world's trees: an identification and information guide. Wallingford: $C A B$ International.

11. Blackman RL. 1981. Aphid genetics and host plant resistance. Bull. SROP 4:13-19.

12. Caillaud MC, Via S. 2000. Specialized feeding behavior influences both ecological specialization and assortative mating in sympatric host races of pea aphids. Am Nat 156:606-621.

13. Blackman RL. 1987. Reproduction, cytogenetics and development. In: Minks AK, Harrewijn P, editors. Aphids: Their biology, natural enemies \& control. Amsterdam: Elsevier.

14. Orlando E. 1974. Sex determination in Megoura viciae Buckton (Homoptera, Aphididae). Monitore Zoologico Italiano (N.S.) 8:61-70.

15. Wilson ACC, Sunnucks $P$, Hales DF. 1997. Random loss of $X$ chromosome at male determination in an aphid, Sitobion near fragariae, detected using an X-linked polymorphic microsatellite marker. Genet Res 69:233-236.

16. Caillaud MC, Boutin M, Braendle C, Simon J-C. 2002. A sexlinked locus controls wing polymorphism in males of the pea aphid, Acyrthosiphon pisum (Harris). Heredity 89:346-352.

17. Shingleton AW, Sisk GC, Stern DL. 2003. Diapause in the pea aphid (Acyrthosiphon pisum) is a slowing but not a cessation of development. BMC Dev Biol 3:7.

18. Sutherland ORW. 1969. The role of crowding in the production of winged forms by two strains of the pea aphid, Acyrthosiphon pisum. J Insect Phys 15:1385-1410. 
19. Mackauer M, Nair KK, Unnithan GC. 1979. Effect of precocene II on alate production in the pea aphid, Acyrthosiphon pisum. Can J Zool 57:856-859.

20. Braendle C, Caillaud MC, Stern DL. 2005. Genetic mapping of aphicarus- a sex-linked locus controlling a wing polymorphism in the pea aphid (Acyrthosiphon pisum). Heredity 94:435-442.

21. Hawthorne DJ, Via S. 2001. Genetic linkage of ecological specialiazation and reproductive isolation in pea aphids. Nature 412:904-907.

22. Via S, Hawthorne DJ. 2002. The genetic architecture of ecological specialization: correlated gene effects on host use and habitat choice in pea aphids. Am Nat 159:S76-S88.

23. Wheeler DE. 1986. Developmental and physiological determinants of caste in social Hymenoptera: evolutionary implications. Am Nat 128:13-34.

24. Shapiro AM. 1976. Seasonal polyphenism. Evolutionary Biology $9: 259-333$.

25. Emlen DJ. 1994. Environmental control of horn length dimorphism in the beetle Onthophagus acuminatus (Coleoptera: Scarabaeidae). Proc R Soc Lond Ser B 256:131-136.

26. Stern DL, Foster WA. 1996. The evolution of soldiers in aphids. Biol Rev Cambridge Phil Soc 71:27-79.

27. Essig EO, Abernathy F. 1952. The aphid genus Periphyllus (Family Aphidae); a systematic, biological, and ecological study. Berkeley: University of California Press.

28. Zera AJ, Denno RF. 1997. Physiology and ecology of dispersal polymorphism in insects. Ann Rev Ent 42:207-230.

29. Kring JB. 1977. Structure of the eyes of the pea aphid, Acyrthosiphon pisum. Annals Ent Soc Am 70:855-860.

30. Muller CB, Williams IS, Hardie J. 2001. The role of nutrition, crowding, and interspecfic interactions in the development of winged aphids. Ecol Ent 26:330-340.

31. Sloggett JJ, Weisser WW. 2002. Parasitoids induce production of the dispersal morphs of the pea aphid, Acyrthosiphon pisum. Oikos 98:323-333.

32. Podjasek JO, Bosnjak LM, Booker DJ, Mondor EB. 2005. Alarm pheromone induces a transgenerational wing polyphenism in the pea aphid, Acyrthosiphon pisum. Can J Zool 83:1138-1141.

33. Kunert G, Otto S, Rose USR, Gershenzon J, Weisser WW. 2005. Alarm pheromone mediates production of winged dispersal morphs in aphids. Ecol Letters 8:596-603.

34. Tsuji H, Kawaka K. 1987. Development and degeneration of wing buds and indirect flight muscles in the pea aphid (Acyrthosiphon pisum (Harris)). Jap J Applied Ent Zool 31:247-252.

35. Hille Ris Lambers L. 1966. Polymorphism in the Aphididae. Ann Rev Ent 11:47-78.

36. Lees AD. 1966. The control of polymorphism in aphids. Adv Ins Phys 3:207-277.

37. Braendle C, Friebe I, Caillaud MC, Stern DL. 2005. Genetic variation for an aphid wing polyphenism is genetically linked to naturally occurring wing polymorphism. Proc Roy Soc London B 272:657-665.

38. Abouheif E, Wray GA. 2002. Evolution of the gene network underlying wing polyphenism in ants. Science 297:249-252.

39. Hardie J. 1980. Juvenile hormone mimics the photoperiodic apterization of the alate gynopara of the aphid Aphis fabae. Nature 286:602-604.

40. Johannsen OA, Butt FH. 1941. Embryology of insects and myriapods. New York: McGraw-Hill Book Co Inc.

41. Miura T, Braendle C, Shingleton A, Sisk G, Kambhampati S, et al. 2003. A comparison of parthenogenetic and sexual embryogenesis of the pea aphid Acyrthosiphon pisum (Hemiptera: Aphidoidea). J Exp Zool B Mol Dev Evol 295B:59-81.
42. Dixon AFG. 1990. Evolutionary aspects of parthenogenetic reproduction in aphids. Acta Phytopath. Entomol. Hung 25:41-56.

43. Blackman RL. 1978. Early development of the parthenogenetic egg in three species of aphids (Homoptera: Aphididae). Int J Insect Morphol Embryol 7:33-44.

44. Blackman RL. 1979. Stability and variation in aphid clonal lineages. Biol J Linnean Soc 1 1:259-277.

45. Simon JC, Rispe C, Sunnucks P. 2002. Ecology and evolution of sex in aphids. Trends Ecol Evol 17:34-39.

46. Simon JC, Delmotte F, Rispe C, Crease T. 2003. Phylogenetic relationships between parthenogens and their sexual relatives: the possible routes to parthenogenesis in animals. Biol J Linn Soc 79:151-163.

47. Maynard Smith J. 1978. The evolution of sex. Cambridge University Press.

48. Williams GC. 1975. Sex and Evolution. Princeton: Princeton University Press.

49. Baumann P, Moran NA, Baumann L. 2000. Bacteriocyte-associated endosymbionts of insects. In: Dworkin $M$, editor. The Prokaryotes. New York: Springer.

50. Wernegreen JJ. 2002. Genome evolution in bacterial endosymbionts of insects. Nature Rev Genet 3:850-861.

51. Moran NA, Wernegreen JJ. 2000. Lifestyle evolution in symbiotic bacteria: insights from genomics. Trends Ecol Evol 8:321-326

52. Klasson L, Andersson SGE. 2004. Evolution of minimal-genesets in hostdependent bacteria. Trends Microb 12:37-43.

53. Shigenobu $S$, Watanabe $H$, Httori $M$, Sakaki $Y$, Ishikawa $H$. 2000. Genome sequence of the endocellular bacterial symbiont of aphids Buchnera sp. APS. Nature 407:81-86.

54. Tamas I, Klasson L, Canback B, Naslund AK, Eriksson AS, et al. 2002. 50 million years of genomic stasis in endosymbiotic bacteria. Science 296:2376-2379.

55. van Ham RCHJ, Kamerbeek J, Palacio C, Rausell C. 2003. Reductive genome evolution in Buchnera aphidicola. Proc Nat Acad Sci USA 100:

56. Buchner P. 1965. Endosymbiosis of animals with plant microorganisms. New York: Interscience Publishers, Inc.

57. Braendle C, Miura T, Bickel R, Shingleton AW, Kambhampati $S$, et al. 2003. Developmental origin and evolution of bacteriocytes in the aphid- Buchnera symbiosis. Plos Biology 1:70-76.

58. Montllor CB, Maxmen A, Purcell AH. 2002. Facultative bacterial endosymbionts benefit pea aphids, Acyrthosiphon pisum, under heat strees. Ecol Ent 27:189-195.

59. Oliver KM, Russell JA, Moran NA, Hunter MS. 2003. Facultative bacterial symbionts in aphids confer resistance to parasitic wasps. Proc Nat Acad Sci USA 100:1803-1807.

60. Kerry OM, Moran NA, Hunter MS. 2005. Variation in resistance to parasitism in aphids is due to symbionts not host genotype. Proc Nat Acad Sci USA 102:12795-12800.

61. Tsuchida T, Koga R, Fukatsu T. 2004. Host plant specialization governed by facultative symbiont. Science 303:1989-1989.

62. Leonardo TE, Mondor EB. 2005. Symbiont modifies host life history traits that affect gene flow. Proc R Soc Lond Ser B in press.

63. Ono M, Swanson JJ, Field LM, Devonshire AL, Siegfried BD. 1999. Amplification and methylation of an esterase gene associated with insecticide-resistance in greenbugs, Schizaphis graminum (Rondani) (Homoptera:Aphididae). Insect Bioch Mol Biol 29:1065-1073.

64. Loxdale HD, Brookes CP, Wynne IR, Clark SJ. 1998. Genetic variability within and between English populations of the damson-hop aphid, Phorodon humuli (Hemiptera: Aphidi- 
dae), with special reference to esterases associated with insecticide resistance. Bull. Ent Res 88: 513-526.

65. Barber MD, Moores GD, Tatchell GM, Vice WE, Denholm I. 1999. Insecticide resistance in the current-lettuce aphid, Nasonovia ribisnigri (Hemiptera: Aphididae) in the U.K. Bull Ent Res 89:17-23.

66. Wang KY, LiU TX, YU CH, Jiang XY, Yi MQ. 2002. Resistance of Aphis gosypii (Homoptera: Aphididae) to fenvalerate and imidacloprid and activities of detoxification enzymes on cotton and cucumber. J Econ Ent 95:407-413.

67. Field LM, Devonshire AL, Forde BG. 1988. Molecular evidence that insecticide resistance in peach-potato aphids (Myzus persicae Sulz.) results from amplification of an esterase gene. Biochem J 251:309-312.

68. Field LM, Foster SP. 2002. Amplified esterase genes and their relationship with other insecticide resistance mechanisms in English field populations of the aphids, Myzus persica (sulzer). Pest Management Science 58:889-894.

69. Gao JR, Kambhampati S, Zhu KY. 2002. Molecular cloning and characterisation of a greenbug (Schizaphis graminum) cDNA encoding acetylcholinesterase possibly evolved from a duplicate gene lineage. Ins Biochem Mol Biol 32:765-775.

70. Thompson M, Steichen JC, Ffrenchconstant RH. 1995. Conservation of Cyclodiene Insecticide Resistance-Associated Mutation in Insects (Vol 2, Pg 149, 1993). Insect Mol Biol 4:124-124.

71. Martinez-Torres D, Foster SP, Field LM, Devonshire AL, Williamson MS. 1999. A sodium channel point mutation is associated with resistance to DDT and pyrethroid insecticides in the peach-potato aphid, Myzus persicae (Sulzer) (Hemiptera: Aphididae). Insect Mol Biol 8:339-346.

72. Andrews MC, Callaghan A, Field LM, Williamson MS, Moores GD. 2004. Identification of mutations conferring insecticideinsensitive AChE in the cotton-melon aphid, Aphis gossypii Glover. Insect Mol Biol 13:555-561.

73. Via S. 1994. Population structure and local adaptation in a clonal herbivore. In: Real LA, editor. Ecological Genetics. Princeton, NJ: Princeton University Press.

74. Via S. 1991. The genetic structure of host plant adaptation in a spatial patchwork: demographic variability among reciprocally transplanted pea aphid clones. Evolution 45:827-852.

75. Via S. 1999. Reproductive isolation between sympatric races of pea aphids. I. Gene flow restriction and habitat choice. Evolution 53:1446- 1457.

76. Pickett JA, Wadhams LJ, Woodcock CM, Hardie J. 1992. The Chemical Ecology of Aphids. Annual Review of Entomology 37:67-90.

77. Hekmat-Scafe DS, Scafe CR, McKinney AJ, Tanouye MA. 2002. Genome-wide analysis of the odorant-binding pro- tein gene family in Drosophila melanogaster. Genome Res 12:1357-1369.

78. Zhou JJ, Huang WS, Zhang GA, Pickett JA, Field LM. 2004. "Plus-C" odorant-binding protein genes in two Drosophila species and the malaria mosquito Anopheles gambiae. Gene 327: 117-129.

79. Gao Q, Chess A. 1999. Identification of candidate Drosophila olfactory receptors from genomic DNA sequence. Genomics 60: 31-39.

80. Kim J, Carlson JR. 2002. Gene discovery by e-genetics: Drosophila odor and taste receptors. J Cell Science 115:1107- 1112 .

81. Jacobs SP, Liggins AP, Zhou JJ, Pickett JA, Jin X, et al. 2005. OS-D-like genes and their expression in aphids (Hemiptera: Aphididae). Insect Mol Biol 14:423-432.

82. Robert Y. 1987. Dispersion and migration. In: Minks AK, Harrewijn $P$, editors. Aphids, their biology, natural enemies, and control. Amsterdam, Netherlands: Elsevier.

83. Pirone TP, Blanc S. 1996. Helper-dependent vector transmission of plant viruses. Ann Rev Phytopath 34:227-247.

84. Liu S, He X, Park G, Josefsson C, Perry KL. 2002. A conserved capsid protein surface domain of cucumber mosaic $\mathrm{Vi}$ rus is essential for efficient aphid vector transmission. J Virol 76:9756-9762.

85. Bauwe H and Kolukisaoglu U. 2003. Genetic manipulation of glycine decarboxylation. J Exp Bot 54:1523-1535.

86. Garret A, Kerlan C, Thomas D. 1996. Ultrastructural study of acquisition and retention of potato leafroll luteovirus in the alimentary canal of its aphid vector, Myzus persicae Sulz Arch Vir 141:1279-1292.

87. Peiffer ML, FGildow FE, Gray SM. 1997. Two distinct mechanisms regulate luteovirus transmission efficiency and specificity at the aphid salivary gland. J Gen Virol 78:495-503.

88. van den Heuvel JFJM, Verbeek M, van der Wilk F. 1994. Endosymbiotic bacteria associated with circulative transmission of potato leafroll virus by Myzus persicae. J Gen Virol 75:2559-2565.

89. van den Heuvel JFJM, Bruyere A, Hogenhout SA, Ziegler-Graff $\mathrm{V}$, Brault $\mathrm{V}$, et al. 1997. The $\mathrm{N}$-terminal region of the luteovirus readthrough domain determines virus binding to Buchnera GroEL and is essential for virus persistence in the aphid. J Virol 71:7258-7265.

90. Li C, Cox-Foster D, Gray SM, Gildow F. 2001. Vector specificity of barley yellow dwarf virus (BYDV) transmission: identification of potential cellular receptors binding BYDV-MAV in the aphid, Sitobion avenae. Virology 286:125-133.

91. Gray SM, Gildow F. Luteovirus-aphid interactions. Ann Rev Phytopath 41:539-566. 